\title{
DRD2 and BDNF Polymorphisms Are Associated With Binge Eating Disorder (BED) in Patients With Weight Regain After Bariatric Surgery
}

Carla Barbosa Nonino ( $\nabla$ carla@fmrp.usp.br)

USP FMRP: Universidade de Sao Paulo Faculdade de Medicina de Ribeirao Preto https://orcid.org/0000-0001-8559-0772

Mariana Barato

FAMERP: Faculdade de Medicina de Sao Jose do Rio Preto

Flávia Campos Ferreira

USP FMRP: Universidade de Sao Paulo Faculdade de Medicina de Ribeirao Preto

Heitor Bernardes Pereira Delfino

USP FMRP: Universidade de Sao Paulo Faculdade de Medicina de Ribeirao Preto

\section{Natalia Yumi Noronha}

USP FMRP: Universidade de Sao Paulo Faculdade de Medicina de Ribeirao Preto

Carolina Ferreira Nicoletti

USP FMRP: Universidade de Sao Paulo Faculdade de Medicina de Ribeirao Preto

Wilson Salgado Junior

USP FMRP: Universidade de Sao Paulo Faculdade de Medicina de Ribeirao Preto

Caroline Rossi Welendorf

USP FMRP: Universidade de Sao Paulo Faculdade de Medicina de Ribeirao Preto

Doroteia Rossi Silva Souza

FAMERP: Faculdade de Medicina de Sao Jose do Rio Preto

Maysa Araújo Ferreira-Julio

FAMERP: Faculdade de Medicina de Sao Jose do Rio Preto

Marcela Augusta de Souza Pinhel

USP FMRP: Universidade de Sao Paulo Faculdade de Medicina de Ribeirao Preto

\section{Research Article}

Keywords: binge eating disorder, polymorphism, obesity, bariatric surgery, weight regain

Posted Date: April 16th, 2021

DOI: https://doi.org/10.21203/rs.3.rs-334784/v1

License: @ (1) This work is licensed under a Creative Commons Attribution 4.0 International License. Read Full License 


\section{Abstract}

Objectives: Verify the frequency of polymorphisms related to obesity and Binge Eating Disorder (BED) in DRD2 and BDNF genes in patients undergoing bariatric surgery with weight regain above $10 \%$ of the weight lost.

Methods: Evaluation of 177 individuals undergoing bariatric surgery with weight regain, divided into two groups: Group 1: individuals with BED; Group 2: individuals without BED. The individuals were submitted to anthropometric evaluation, analysis of the presence of BED using a validated questionnaire, and blood collection for genotyping of the polymorphisms, rs6265 (BDNF) and rs1800497(DRD2). The Kolmogorovi-Smirnov, t-test, chi-square, Mann Whitney, Pearson correlation were used for statistical analysis.

Results: CC genotypes for $r 51800497$ polymorphism, and GG for $r s 6265$ polymorphism were more frequent in patients without the disorder. The presence of at least one $T$ allele (DRD2) and at least one $A$ allele (BDNF) was more frequent in patients with BED. The combination of $A A$ $+G A+T T+T C$ genotypes prevailed in patients with the disorder.

Conclusions: The $C C$ (DRD2) and $G G(B D N F)$ genotypes suggest protection for patients against BED, while genotypes that have at least one $T$ allele (DRD2) and one $A$ allele (BDNF) suggest greater risk and appear to act in synergism.

Level of evidence: III (evidence obtained from case-control analytic study).

\section{Introduction}

Binge eating disorder (BED) is one of the most common eating disorders, being characterized by recurrent episodes of binge eating that occur at least once a week for three months, associated with lack of control and pronounced suffering. Binge eating episodes are generally associated with aspects such as eating faster than normal, eating more than gastric capacity, eating in large quantities in the absence of physical hunger, and feeling guilty about binge eating, compromising physical and psychosocial health significantly [1-3]. However, this disorder is not associated with inappropriate compensatory strategies after binge eating, which is why BED is often associated with obesity $[1,4-5]$. The prevalence of BED is estimated at 2 to $3.5 \%$ and is observed in 5 to $30 \%$ of individuals with obesity [2-3].

The etiology of binge eating disorder (BED) is multifactorial, involving genetic, psychological, and sociocultural factors. Among the genetic aspects, we highlight the single nucleotide polymorphisms (SNP), which are examples of genetic modifications, which can significantly influence the regulation of neural circuits that control the appetite/satiety pathway, as well as the regulation of cerebral reward systems $[2,5]$. Although SNPs are not the only determining factors, they indicate a genetic predisposition for the individual to develop metabolic disorders [6].

Several genes can be associated with overweight and eating disorders [7]. An example is the DRD2 gene (dopamine D2 receptor), which encodes the dopamine receptor type D2 [8]. This receptor is in the presynaptic membrane of dopaminergic neurons and has the function of modulating the release of dopamine in the synaptic cleft in the reward system of the dopaminergic pathways [9]. The SNP rs1800497 is associated with disorders such as binge eating [10]. Since the presence of one or two copies of this polymorphism is related to the reduction in the density of D2 receptors in the mesolimbic areas of the reward system, which suggests that individuals with reduction of this regulatory receptor tend to present behaviours that stimulate the release of dopamine [11], as well as in the use of drugs of abuse [12] and in the binge eating [13].

Another gene of interest is the BDNF (brain-derived neurotrophic factor) gene, which plays an important role in regulating weight, appetite, and satiety by stimulating the release of hormones such as somatostatin, the thyrotrophin-releasing hormone (TRH) and the corticotrophinreleasing hormone $(\mathrm{CRH})$ in the hypothalamus $[8,14]$. The presence of the rs 6265 polymorphism has been associated with eating disorders and obesity in different populations [15-16]. Other SNPs present in this gene, such as rs925946, rs10501087 and rs988712, may also be related to genetic determinants of overweight and obesity [17].

Obesity is a complex multifactorial disease, related to the excessive accumulation of fat that can cause health problems. It is estimated that 1.9 billion adults are overweight in the world, 650 million of whom are obese [18]. There are several risk factors for obesity, among them: genetic factors, from which several markers related to susceptibility to overweight, family history, psychological aspects and socio-cultural and economic context have been identified. In addition, obesity is associated with several other diseases such as depression, type 2 diabetes, cardiovascular disease, cancer, and others [19].

Among the various treatments for obesity control, the traditional ones are the first choice for the patient, which consist of lifestyle changes, associated with eating and physical exercise. There are also surgical methods, including gastric bypass, a procedure performed as a 
treatment to control severe obesity based on the patient's body mass index (BMI), the presence of comorbidities and time of previous clinical treatment [20].

The average weight loss due to bariatric surgery is 60 to $75 \%$ of excess weight. However, weight regain is observed substantially in many patients, after a few years of surgery. Several studies show that after 24 months weight regain begins, with a weight gain observed in $28.1 \%$ of the patients, reaching $41 \%$ after 10 years of the surgical procedure, indicating that the regain is progressive in the long term [21-24].

Weight regain is a complex, multifactorial mechanism, and is related to several factors such as lifestyle, mental health, hormones, surgical technique, inadequate diet [25], alcohol consumption [26] and physical inactivity [27]. Together, eating disorders, which are often observed in bariatric patients, can significantly impact the outcome of bariatric surgery, and may be another contributing factor to weight regain [28].

In this context, given the important participation of genetic factors in the development of obesity and eating disorders, and considering that this is a disease that affects millions of individuals worldwide, leading to incapacitation and consequent damage also to public coffers, it is made necessary to elucidate molecular mechanisms involved with obesity to apply personalized medicine. Thus, the objective of the study was to verify the frequency of SNPs related to obesity and binge eating present in the DRD2 and BDNF genes in patients with weight regain in the postoperative period of bariatric surgery who have or not binge eating disorder (BED).

\section{Materials And Methods}

Were evaluated 177 individuals aged 18 to 65 years, of mixed race, of both sexes, with recurrence greater than $10 \%$ of the total weight lost, after bariatric surgery. The individuals were monitored by the Bariatric Surgery Outpatient Clinic of the Clinical Hospital of the Ribeirao Preto Medical School (HCFMRP) and the Base Hospital of Sao Jose do Rio Preto and were divided into two groups: Group 1 (G1) - patients with BED; Group 2 (G2) - patients without BED. The study was approved by the Research Ethics Committee of the Sao Jose do Rio Preto Medical

School (FAMERP) (CAAE number 65678117.7.0000.5415) and by the Research Ethics Committee of the Ribeirao Preto Medical School of the University of Sao Paulo (Process 14375/2018), and all participants signed the Free and Informed Consent Form (FICF). Patients under 18 or over 65 with a history of liver disease were excluded from the study; anticoagulated or with coagulation disorders; pregnant women; severe malnourished, anemic, chronic alcohol users or drug users; with a history of recent neoplasia; reoperated or with immediate or late postoperative complications.

Anthropometric measurements (height $(A)$, body weight $(P)$ and body mass index (BMI) were performed at three specific times: before surgery (P1); two years after surgery (P2), and more than 5 years after surgery (P3) Peripheral blood was also collected for genetic analysis of the SNPs and the Binge Eating Scale (BES) was applied [29], for patient distribution in the studied groups (G1 and G2) according to the score in the questionnaire, patients with scores less than or equal to 17 were allocated to G2 (without BED) and patients above 17 points were allocated to $\mathrm{G} 1$ (with BED).

\section{Anthropometric assessment}

For anthropometric assessment, the following indicators were used: weight, height, BMI and weight regain (\%). The patients were weighed on a Filizola ${ }^{\circledR}$ digital scale, platform type, with a capacity of $300 \mathrm{~kg}$ and precision of $0.2 \mathrm{~kg}$. To measure height, a vertical nail with a $0.5 \mathrm{~cm}$ graduation was used. The BMI was obtained using the formula BMI = W/ $\mathrm{H}^{2}$, for the three weighing periods (W1, W2 and W3); to calculate the percentage of weight regain (WR), the formula WR $=100 \times(\mathrm{P} 3$ - P2) / (P1 - P2); to calculate the ideal weight (IW), that is, BMI = $25 \mathrm{Kg} /$ $\mathrm{m}^{2}$, IW $=25 \times \mathrm{H}^{2}$; to calculate the current excess weight $(\mathrm{EW})$, the formula $\mathrm{EW}=\mathrm{W} 3-\mathrm{IW}$.

\section{Genetic analysis}

DNA extraction from the peripheral blood sample was performed with a GE Healthcare kit (Illustra blood genomic Prep Mini Spin kit), according to the supplier's guidelines, using $200 \mu \mathrm{L}$ of the extracted material. Subsequently, the DNA was eluted in water and the concentration adjusted to $50 \mu \mathrm{g} / \mu \mathrm{L}$, with the aid of the Qubit 2.0 spectrophotometer (Invitrogen ${ }^{\circledR}$ ). After this analysis, they were stored at -80 ${ }^{\circ} \mathrm{C}$ in aliquots, aiming at stability and preservation of the DNA, thus avoiding the degradation of the material. DNA genotyping for analysis of rs 1800497 SNP of the DRD2 gene and rs6265 SNP of the BDNF gene was performed by Real-Time Polymerase Chain Reaction (RT-PCR), using the 7500 Fast - Applied Biosystems ${ }^{\circledR}$ equipment. Genotyping was performed using the TaqMan Pre-Designed SNP Genotyping Assays kit (Applied Biosystems, Foster City, CA), following the manufacturer's standards.

\section{Statistical Analysis}

The normality of data distribution was verified by the Kolmogorov-Smirnov test, the descriptive statistics was composed of mean and standard deviation values. Mann Whitney's post hoc test $t$ analysis was applied to verify differences between groups. The odds ratio was 
calculated to check the odds ratio for BED in selected patients. Correlation analysis between genetic and anthropometric variables were performed using Pearson's correlation coefficient. Allele and genotype frequencies were analysed using the Chi-square or Fisher's tests. The Hardy-Weinberg equilibrium calculation was performed which evaluates if allele and genotype frequencies in a population will remain constant from one generation to next generation in the absence of disturbing factors. Statistical significance ( $p$-value) was established at $p$ $<0.05$. The analysis was performed using the Statistical Package for Social Science software (SPSS version 20.0 [Inc. Chicago. IL]).

\section{Results}

Table 1 presents the sociodemographic and anthropometric data of patients with obesity who underwent bariatric surgery and had a weight regain $>10 \%$ in the postoperative period $(N=177)$, distributed in groups with BED $(N=94)$ and without $B E D(N=83)$. The analysis showed that the groups with and without BED did not differ from each other for all assessed variables $(p>0.05)$. The female gender prevailed in both groups ( $89 \%$ and $81 \%$ for the groups with and without BED, respectively), with no statistically significant difference between them ( $p=0.136)$. The mean age did not differ between the groups, being $41.0 \pm 9.6$ years for the group with BED and $41.2 \pm 10.5$ years for those without the disorder $(p=0.901)$. Regarding weight and BMI, a significant reduction in these variables was noted when comparing the pre-surgery periods and after weight loss in the post-surgery period, for both groups $(p<0.01)$. On the other hand, the percentage of weight regain for the BED group was $22.02 \%$ and $25.93 \%$ for the group without the disorder $(p=0.471)$.

Table 1

Sociodemographic and anthropometric data of patients with and without Binge Eating Disorder (BED).

\begin{tabular}{|c|c|c|c|c|c|c|c|c|c|c|c|c|c|}
\hline Variables & \multicolumn{6}{|c|}{ With BED (a) } & \multicolumn{6}{|c|}{ Without BED (b) } & $\begin{array}{l}\text { Value } \\
p\end{array}$ \\
\hline & \multicolumn{6}{|l|}{$N=94$} & \multicolumn{7}{|l|}{$N=83$} \\
\hline Sociodemographic & \multicolumn{3}{|l|}{$\mathbf{N}$} & \multicolumn{3}{|l|}{$\%$} & \multicolumn{3}{|l|}{$\mathbf{N}$} & \multicolumn{4}{|l|}{$\%$} \\
\hline Female & \multicolumn{3}{|l|}{84} & \multicolumn{3}{|l|}{89} & \multicolumn{3}{|l|}{67} & \multicolumn{3}{|l|}{81} & 0,136 \\
\hline \multirow[t]{2}{*}{ Male } & \multicolumn{3}{|l|}{10} & \multicolumn{3}{|l|}{11} & \multicolumn{3}{|l|}{16} & \multicolumn{4}{|l|}{19} \\
\hline & \multicolumn{2}{|c|}{ Pre-surgery (c) } & \multicolumn{2}{|c|}{$\begin{array}{l}\text { Post-surgery } \\
\text { (minimum } \\
\text { weight) (d) }\end{array}$} & \multicolumn{2}{|c|}{ Post-regain (e) } & \multicolumn{2}{|c|}{ Pre-surgery (f) } & \multicolumn{2}{|c|}{$\begin{array}{l}\text { Post-surgery } \\
\text { (minimum } \\
\text { weight) (g) }\end{array}$} & \multicolumn{2}{|c|}{ Post-regain (h) } & \\
\hline Anthropometric & $M$ & SD & $M$ & SD & $M$ & SD & M & SD & $M$ & SD & $M$ & SD & \\
\hline Height & 1.63 & 0.083 & - & - & - & - & 1.63 & 0.088 & - & - & - & - & 0.716 \\
\hline Age & 41.02 & 9.65 & - & - & - & - & 41.30 & 10.57 & - & - & - & - & 0.901 \\
\hline Regain (\%) & 22.02 & 15.22 & - & - & - & - & 26.32 & 34.14 & - & - & - & - & 0.471 \\
\hline Ideal weight & 66.22 & 6.79 & - & - & - & - & 67.13 & 7.22 & - & - & - & - & 0.732 \\
\hline Overweight & 26.15 & 15.07 & - & - & - & - & 29.31 & 19.21 & - & - & - & - & 0.426 \\
\hline Weight & 133.4 & 22.94 & 83.49 & 15.45 & 92.57 & 16.52 & 132.4 & 27.26 & 86.48 & 19.62 & 94.24 & 20.75 & \#\# \\
\hline BMI & 49.41 & 7.32 & 31.00 & 5.54 & 34.64 & 5.86 & 49.05 & 8.20 & 31.69 & 6.28 & 35.40 & 7.71 & \#\# \\
\hline \multicolumn{14}{|c|}{ 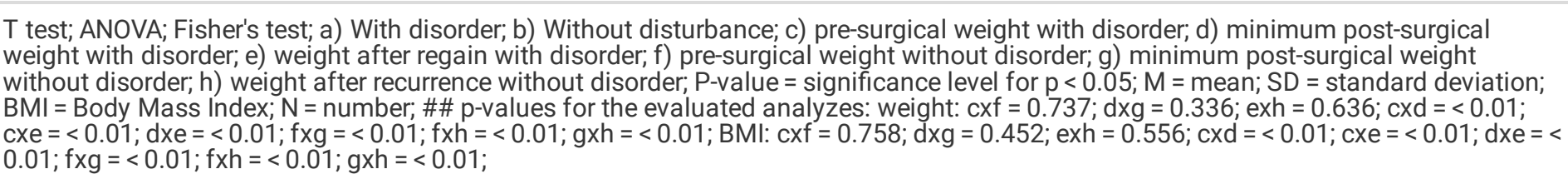 } \\
\hline
\end{tabular}

There was no significant difference in weight comparison for groups with and without BED in the preoperative $(p=0.737)$, postoperative $(p=$ $0.336)$ and after regain $(p=0.636)$ periods. The same occurred for the BMI variable, showing that the groups studied (with and without BED) are homogeneous for these indicators.

Table 2 shows the genotype and allele frequency of the rs 1800497 polymorphism for the DRD2 gene in patients with and without BED. In this case, it was found that the CC genotype was more frequent in patients without BED (67.5\%), when compared to the group with BED (44.7\% $\mathrm{p}$ $=0.004)$; On the other hand, the presence of the $C T$ genotype (48.9\%) and T allele (0.31) were prevalent in the BED group compared to the 
group without the disease $(27.7 \%$ and 0.19 , respectively; $p=0.006$ and $p=0.012)$, showing its possible risk character for the disorder $\mathrm{In}$ addition, the presence of at least one $T$ allele was favourable to binge eating $(55.5 \% ; p=0.004)$.

Table 2

Genotype and allele frequency of rs 1800497 polymorphism for DRD2 gene in patients with and without Binge Eating Disorder (BED)

\begin{tabular}{|c|c|c|c|c|c|}
\hline \multirow{2}{*}{$\begin{array}{l}\text { DRD2 polymorphism }(C>T) \\
\text { Genotypes }\end{array}$} & \multicolumn{2}{|c|}{ With BED } & \multicolumn{2}{|c|}{ Without BED } & \multirow[t]{2}{*}{ Value $p(\mathrm{OR} / \mathrm{Cl})$} \\
\hline & \multicolumn{2}{|c|}{$N=94$} & \multicolumn{2}{|c|}{$N=83$} & \\
\hline & $\mathbf{N}$ & $\%$ & $\mathbf{N}$ & $\%$ & \\
\hline \multirow[t]{2}{*}{$C C$} & 42 & 44.7 & 56 & 67.5 & 0.004 \\
\hline & & & & & $0.38 /(0.21-0.71)$ \\
\hline \multirow[t]{2}{*}{$C T$} & 46 & 48.9 & 23 & 27.7 & 0.006 \\
\hline & & & & & $2.50 /(1.33-4.68)$ \\
\hline \multirow[t]{2}{*}{$T T$} & 6 & 6.4 & 4 & 4.8 & 0.751 \\
\hline & & & & & $1.34 /(0.36-4.94)$ \\
\hline Total & 94 & 100 & 83 & 100 & 0.004 \\
\hline$-T$ & 52 & 55.3 & 27 & 32.5 & $2.56 /(1.30-4.70)$ \\
\hline Alleles & $\mathbf{N}$ & Abs. Freq. & $\mathbf{N}$ & Abs. & \\
\hline$C$ & 130 & 0.69 & 135 & 0.81 & 0.012 \\
\hline$T$ & 58 & 0.31 & 31 & 0.19 & $0.51 /(0.31-0.84)$ \\
\hline Total & 188 & 1 & 166 & 1 & \\
\hline
\end{tabular}

Fisher's exact test or $\mathrm{X}^{2} ; \mathrm{OR}=$ Odds Ratio; $\mathrm{Cl}=$ Confidence Interval; $\mathrm{p}$ value = significance level for $\mathrm{p}<0.05 ; \mathrm{Abs}$ freq $=\mathrm{Absolute}$ Frequency; $\mathrm{N}=$ number

Figure 1 shows the frequency for each genotype represented in Table 2, in which it is possible to verify that the genotype frequency $C C$ is higher in patients without BED, the genotype $C T$ is more common in patients with BED, as well as the presence of at least one $T$ allele ( $p<$ 0.05 for all these combinations).

Table 3 shows the genotypic and allele frequency of the rs6265 polymorphism for the BDNF gene in patients with and without BED. Thus, it was observed that the $G G$ genotype and $G$ allele were prevalent in patients without BED ( $81.9 \%$ and 0.91 respectively) when compared to the group with BED (66\% and 0.82, respectively; $p=0.017$ and 0.020$)$, showing a possible protective character for the disorder. The $G A$ and $A$ genotypes prevailed in the group with the disorder (33\% and 34\%) compared to the group without the disorder (18.1 and $18 \%$; respectively; $p$ $=0.026$ and 0.025 ), possibly favouring the appearance of BED. On the other hand, the frequency of the $G$ allele was protective for BED ( $p=$ $0.020)$. 
Table 3

Genotype and allele frequency of rs6265 polymorphism for the BDNF gene in patients with and without Binge Eating Disorder (BED)

\begin{tabular}{|c|c|c|c|c|c|}
\hline \multirow{2}{*}{$\begin{array}{l}B D N F \text { polymorphism }(G>A) \\
\text { Genotypes }\end{array}$} & \multicolumn{2}{|c|}{ With BED } & \multicolumn{2}{|c|}{ Without BED } & \multirow[t]{2}{*}{ Value $p(\mathrm{OR} / \mathrm{Cl})$} \\
\hline & \multicolumn{2}{|c|}{$N=94$} & \multicolumn{2}{|c|}{$N=83$} & \\
\hline & $\mathbf{N}$ & $\%$ & $\mathbf{N}$ & $\%$ & \\
\hline \multirow[t]{2}{*}{$G G$} & 62 & 66.0 & 68 & 81.9 & 0.017 \\
\hline & & & & & $0.42 /(0.21-0.86)$ \\
\hline \multirow[t]{2}{*}{$G A$} & 31 & 33.0 & 15 & 18.1 & 0.026 \\
\hline & & & & & $2.23 /(1.10-4.51)$ \\
\hline \multirow[t]{2}{*}{$A A$} & 1 & 1.1 & 0 & 0 & 1.000 \\
\hline & & & & & $2.67 /(0.10-66.7)$ \\
\hline Total & 94 & 100 & 83 & 100 & 0.025 \\
\hline${ }^{A}$ & 32 & 34 & 15 & 18 & $2.34 /(1.10-4.70)$ \\
\hline Alleles & $\mathbf{N}$ & Abs. Freq. & $\mathbf{N}$ & Abs. & \\
\hline$G$ & 155 & 0.82 & 151 & 0.91 & 0.020 \\
\hline$A$ & 33 & 0.18 & 15 & 0.09 & $0.46 /(0.24-0.89)$ \\
\hline Total & 188 & 1 & 166 & 1 & \\
\hline
\end{tabular}

Fisher's exact test or $\mathrm{X}^{2}$; OR = Odds Ratio; $\mathrm{Cl}=$ Confidence Interval; P-value = significance level for $\mathrm{p}<0.05 ; \mathrm{Abs}$ freq = Absolute Frequency; $\mathrm{N}=$ number

Figure 2 shows the frequency for each genotype represented in Table 3, where it is possible to verify that the GG genotype frequency is higher in patients without BED, the $G A$ genotype is more common in patients with BED, as well as the presence of at least one allele $A$ ( $p<0.05$ for all these combinations).

Table 4 shows the genotypic combinations for the evaluated polymorphisms (rs1800497from the DRD2 gene and rs6265 from the BDNF gene). In this case, it was observed that the combination of genotypes with at least one T allele for the rs1800497 polymorphism and one A allele for the rs6265 polymorphism was more frequent in those patients with BED (18\%) compared to the group without the disorder $(7 \%$; $p=$ 0.002), pointing out that in synergism these two polymorphisms can predispose to binge disorder.

Both groups were within the Hardy-Weinberg balance $(\mathrm{p}>0.05)$ for the DRD2 $(\mathrm{X} 2=0.225)$ and $B D N F(\mathrm{X} 2=2.089)$ polymorphisms.

Table 4

Genotypic combination for the DRD2 gene rs1800497 and the BDNF gene rs6265 polymorphisms in patients with and without Binge Eating Disorder (BED)

\begin{tabular}{|c|c|c|c|c|c|}
\hline \multirow[t]{3}{*}{ Variables } & \multicolumn{2}{|c|}{ With BED } & \multicolumn{2}{|c|}{ Without BED } & \multirow[t]{2}{*}{ Value p (OR/Cl) } \\
\hline & \multicolumn{2}{|c|}{$N=94$} & \multicolumn{2}{|c|}{$N=83$} & \\
\hline & $\mathbf{N}$ & $\%$ & $\mathbf{N}$ & $\%$ & \\
\hline$A A+G A+T T+T C$ & 17 & 18 & 6 & 7 & 0,002 \\
\hline$G G+C C$ & 27 & 29 & 47 & 57 & $4.93 /(1.73-14.01)$ \\
\hline
\end{tabular}

When the mean values and standard deviations of the BMI were analyzed in relation to the presence of the genotypes of the studied polymorphisms, it was observed that there was no statistically significant difference between the groups with and without the disorder, with $p>0.05$ for all studied genotypes. (Table 5). 
Table 5

Mean values and standard deviations of the BMI of patients with and without Binge Eating Disorder (BED) in relation to the genotypes for the DRD2 gene rs1800497 and the BDNF gene rs6265 polymorphisms

\begin{tabular}{|c|c|c|c|c|c|c|c|c|c|c|}
\hline \multirow{3}{*}{ Variables } & \multicolumn{4}{|c|}{ With BED } & \multicolumn{4}{|c|}{ Without BED } & \multicolumn{2}{|c|}{ Value $p$} \\
\hline & \multicolumn{2}{|c|}{ Pre-surgery (a) } & \multicolumn{2}{|c|}{ Post-regain (b) } & \multicolumn{2}{|c|}{ Pre-surgery (c) } & \multicolumn{2}{|c|}{ Post-regain (d) } & \multirow[t]{2}{*}{ axc } & \multirow[t]{2}{*}{ bxd } \\
\hline & M & SD & $\mathbf{M}$ & SD & $\mathbf{M}$ & SD & M & SD & & \\
\hline \multicolumn{11}{|l|}{ DRD2 } \\
\hline$C C$ & 49.17 & 7.80 & 35.07 & 6.05 & 48.34 & 7.36 & 36.28 & 8.64 & 0.657 & 0.535 \\
\hline$C T$ & 49.50 & 7.28 & 34.50 & 5.70 & 47.33 & 9.00 & 33.87 & 5.77 & 0.349 & 0.725 \\
\hline$T T$ & 50.5 & 4.42 & 33.00 & 6.60 & - & - & - & - & - & - \\
\hline$\perp T$ & 49.61 & 6.98 & 34.30 & 5.75 & 47.25 & 8.70 & 33.81 & 5.58 & 0.268 & 0.777 \\
\hline \multicolumn{11}{|l|}{ BDNF } \\
\hline$G G$ & 49.68 & 7.31 & 35.40 & 5.64 & 48.40 & 7.75 & 35.31 & 8.14 & 0.421 & 0.960 \\
\hline$G A$ & 48.39 & 6.96 & 32.78 & 5.70 & 46.4 & 8.09 & 35.70 & 6.38 & 0.455 & 0.202 \\
\hline$A A$ & - & - & - & - & - & - & - & - & - & - \\
\hline$\perp A$ & 48.91 & 7.45 & 33.29 & 6.11 & 46.4 & 8.09 & 35.70 & 6.38 & 0.368 & 0.308 \\
\hline
\end{tabular}

The analysis carried out between BMI values and the patients' scores on the BES revealed a positive correlation between the referred variables $(r=0.320 ; p=0.015)$.

Correlation between BMI and BED $(r=0.320 ; p=0.015)$.

\section{Discussion}

In this study, the presence of genotypes with at least one _ $/ T$ allele for the $r s 1800497$ SNP of the DRD2 gene, and _ / A for the $r s 6265$ SNP of the $B D N F$ gene were more prevalent in patients with BED. These data corroborate with other studies, which also show an association of these polymorphisms with the disease [10, 30-31]. It is known that the presence of these polymorphisms, especially the rs 1800497 in DRD2 gene, is associated with reduced dopamine function in the brain [32-33] by about 30 to $40 \%$ of the normal value [5]. In addition, they seem to be related to increased BMI and eating disorders in women with bulimia spectrum disorder [34-35], being considered a possible marker for high risk of developing pathological eating behavior [36]. In addition, other studies show that the presence of the $T$ allele for the $D R D 2 \mathrm{gene}$ is associated with unhealthy eating, abnormal levels of glucose and triglycerides [37], other addictive behaviors combined with overweight [38], obesity [39], hedonic diet [40], and high sensitivity to reward [41], which directly influences the increase in caloric intake [42]. However, it is important to note that these variables were not evaluated in this study.

The findings of the present study show that the presence of at least one $T$ allele was prevalent in patients with obesity associated with BED, as compared to the control group (with obesity and without BED). Therefore, the presence of at least one $T$ allele was favorable to binge eating $(\mathrm{p}=0.004)$. This result corroborates with the literature that points to a higher prevalence of the rs 1800497 SNP of the DRD2 gene among individuals with the disorder $[10,30]$. This prevalence supports the view that this eating disorder may be related to hypersensitivity to the reward, this polymorphism being a predisposition favored by facilitated access to highly palatable and caloric foods [30]. On the other hand, another study, also comparing groups with obesity with and without BED, found the prevalence of the $T$ allele in the group without the disorder [43], while another found no significant difference between the groups [44], showing that the results are conflicting.

Still regarding the DRD2 gene polymorphism, it is reported in the literature that the $T T$ genotype is associated with increased body fat and increased adiposity compared to the $C T$ and $C C$ genotypes [33]. However, the low frequency of the referred genotype in the present study can be considered a limitation, mainly due to its sample size. Therefore, it was not possible to evaluate its effect. In addition, there was no correlation between pre-surgical and post-surgical BMI for patients with and without BED for each of the analyzed genotypes (Table 5). 
As for the SNP rs6265 of the BDNF gene, studies have shown that the presence of polymorphism is associated with obesity [15, 45], as well as overweight in childhood [46-48]. The present study showed a predominance of the GA genotype in individuals with BED ( $p=0.025)$, revealing that the presence of at least one $A$ allele can be an aggravating factor for BED (Odds Ratio: 2.34; Confidence Interval: 1,10 - 4.7; $p$ $=0.025$ ). However, another study involving three groups of patients (bulimia nervosa, BED and healthy controls), all female, revealed that in the BED group, individuals with the $A A$ genotype exhibited a significantly greater severity of binge eating than those with $G A$ and $G G$ genotype [49]. The analysis in the present study for the $A A$ genotype was not possible because only one patient had such a genotype.

In another study, they analyzed the interaction of the rs6265SNP of the BDNF gene and sex. Thus, men with the GG genotype had higher $\mathrm{BMI}$, waist circumference, and weight than those with $G A$ or $A A$. On the other hand, women with the GG genotype had a significantly lower BMI than those with $G A$ or $A A$. Thus, the rs6265 SNP of the BDNF gene is associated with the risk of obesity in different ways according to sex [15]. A study conducted only with female patients found an association between obesity and the presence of the $A$ allele [31]. Another study conducted with female patients did not find differences in genotype frequency between the groups with or without BED [44]. However, the present study did not carry out an analysis to investigate the predominance of the genotype between the sexes, due to the prevalence of females in $85 \%$ of the sample. However, it is important to note that in the present series, the GG genotype proved to be a protective factor for obesity (Odds Ratio: 0.42; Confidence interval: 0.21-0.86; $p=0.017$ ) and the GA genotype, aggravating factor (Odds Ratio: 2.23; Confidence interval: 1.10-4.51).

The analysis combining genotypes of the two studied polymorphisms revealed that the presence of at least one $T$ allele for the $D R D 2$ gene polymorphism (rs1800497) and an $A$ allele for the BDNF gene polymorphism (rs6265) were predominant in the BED group ( $p=0.002$ ). The literature evaluating the combination of these polymorphisms is scarce, however in view of the data obtained in this study, a possible synergism was observed between these genetic variants, since the function of both genes is related to the addiction of chemical substances such as alcohol and cocaine [50-52], psychiatric disorders [53-54] and eating disorders [38, 49].

Weight regain was present in both groups of obese patients with or without BED. However, there was no difference in the mean BMI between the groups for each of the studied genotypes. The literature on weight regain for the polymorphisms studied is scarce, however, a study revealed that no effect was detected on the presence of rs6265SNP of the BDNF gene and weight gain throughout life in patients followed from 40 to 70 years of age [55]. In addition, a study that followed 1406 patients for more than six years after bariatric surgery revealed that more than $67 \%$ of patients recover $20 \%$ or more of the weight lost in the first two years [23]. In this context, obesity is characterized as a multifactorial disease, and the evidence presented by the literature indicates that even after different types of treatments for weight loss (surgical or not), a regain occurs over the years. Thus, several factors, including genetics, can act for this "new" weight gain after treatments.

The presence of the two polymorphisms studied (rs1800497SNP of the DRD2 gene, and GG for rs6265 SNP of the BDNF gene) suggest that there may be a reduction in gene expression for both genes and pre-disposition to binge eating. The presence of the $r s 1800497$ SNP of the $D R D 2$ gene has been associated with a reduction in the density of type 2 dopamine receptors in the presynaptic membrane of the mesolimbic pathways, causing an increase in the concentration of dopamine in the synaptic cleft and contributing to behavior of abuse and compulsion [13]. The rs6265SNP of the BDNF gene was related to the decrease in the production of neurotrophins that act in the hypothalamus and stimulate the production of hormones related to satiety such as TRH and CRH [14].

The strength of this study is related to the significant association of the evaluated polymorphisms and BED. The literature addressing this association is scarce and in the present study, even with a reduced sample, it was possible to observe this effect. On the other hand, the main limitation of this study refers to the small sample size. However, this factor was not limiting enough to show the association of the studied polymorphisms both independently and in synergism. In addition, the absence of a eutrophic group can also be considered a limitation. Since studies involving the frequency of these SNPs with BED in eutrophic individuals are also scarce or nonexistent in the literature. Fact that could assist in elucidating the prevalence of these genetic variants in eutrophic casuistry.

\section{Conclusion}

In conclusion, the CC genotypes for the DRD2 gene rs 1800497 and GG for the BDNF gene rs6265 polymorphisms seem to protect patients from this BED case series, due to their higher prevalence in the group without the disease. On the other hand, the presence of at least one $T$ allele (DRD2) and at least one $A$ allele $(B D N F)$ confers a higher risk for the development of BED. The combination of the referred genotypes $(A A+G A+T T+T C)$ of the evaluated polymorphisms is associated with the presence of the disorder. Weight regain is similarly frequent for both groups. In addition, the BMI of patients with and without the disorder do not correlate with the different genotypes of the evaluated polymorphisms, showing that weight regain appears to have a multifactorial character.

\section{What is already known on this subject?}


There is no consensus in the literature on the presence of the studied polymorphisms (rs1800497 SNP of the DRD2 gene and rs6265 SNP of the BDNF gene) in individuals with obesity and BED.

\section{What this study adds?}

This study adds that the presence of genotypes with at least one _ / $T$ allele for the $r s 1800497$ SNP of the $D R D 2$ gene, and _ / $A$ for the rs6265 SNP of the BDNF gene were more prevalent in patients with BED and obesity, suggesting a possible synergism between these genetic variants and additional risk for BED.

\section{Declarations}

\section{Funding}

This research was supported by São Paulo Research Foundation (FAPESP) (\#grants numbers: 2018/24069-3, 2018/08784-4 and 2013/12819-4] and National Council for Scientific and Technological Development (CNPq) [\#grant No. 480763/2013-5].

\section{Conflicts of interest/Competing interests}

The authors declare no conflict of interest. The funders had no role in the design of the study; in the collection, analysis, or interpretation of data; in the writing of the manuscript, or in the decision to publish the results.

\section{References}

1. [APA] American Psychiatric Association. Diagnostic and statistical manual of mental disorders: DSM-5 (5th ed.). Washington, DC: American Psychiatric Association.

2. Yilmaz Z, Hardaway JA, Bulik CM (2015) Genetics and Epigenetics of Eating Disorders. Adv Genomics Genet. 5:131-150.

3. Brownley KA, Berkman ND, Peat CM, Lohr KN, Cullen KE, Bann CM, Bulik CM (2016) Binge-Eating Disorder in Adults: A Systematic Review and Meta-analysis. Ann. Intern. Med. 165(6): 409-420.

4. da Luz FQ, Hay P, Touyz S, Sainsbury A (2018) Obesity with Comorbid Eating Disorders: Associated Health Risks and Treatment Approaches. Nutrients, 10(7), 829.

5. Nicoletti CF, Delfino HBP, Ferreira FC, Pinhel MAS, Nonino CB (2019) Role of eating disorders-related polymorphisms in obesity pathophysiology. Rev Endocr Metab Disord. 20(1):115-25.

6. Ghalandari H, Hosseini-Esfahani F, Mirmiran P (2015) The Association of Polymorphisms in Leptin/Leptin Receptor Genes and Ghrelin/Ghrelin Receptor Genes With Overweight/Obesity and the Related Metabolic Disturbances: A Review. Int J Endocrinol Metab. 13(3):e19073.

7. Alonso R, Farías M, Alvarez V, Cuevas A (2016) Translational Cardiometabolic Genomic: The Genetics of Obesity. Boston: Academic Press.

8. [NCBI] National Center for Biotechnology Information - National Library of Medicine: Gene DRD2 and Gene BDNF (2020) Bethesda, MD. [accessed 2020 Apr 22]. https://www.ncbi.nlm.nih.gov/gene/1813.

9. Mishra A, Singh S, Shukla S (2018) Physiological and Functional Basis of Dopamine Receptors and Their Role in Neurogenesis: Possible Implication for Parkinson's disease. J Exp Neurosci. 12:1-8.

10. Palacios A, Canto P, Tejeda ME, Stephano S, Luján H, García-García E, Rojano-Mejía D, Méndez JP (2018) Complete sequence of the ANKK1 gene in Mexican-Mestizo individuals with obesity, with or without binge eating disorder. Eur Psychiatry.54:59-64.

11. Ritchie T, Noble EP (2003) Association of seven polymorphisms of the D2 dopamine receptor gene with brain receptor-binding characteristics. Neurochem Res. 28(1):73-82.

12. Spellicy CJ, Harding MJ, Hamon SC, Mahoney JJ 3rd, Reyes JA, Kosten TR, Newton TF, De La Garza R 2nd, Nielsen DA (2014) A variant in ANKK1 modulates acute subjective effects of cocaine: a preliminary study. Genes Brain Behav. 13(6):559-64.

13. Baik JH (2013) Dopamine signaling in food addiction: role of dopamine D2 receptors. BMB reports. 46(11):519-26.

14. Tapia-Arancibia L, Rage F, Givalois L, Arancibia S (2004) Physiology of BDNF: focus on hypothalamic function. Front Neuroendocrinol. 25(2):77-107.

15. Ma XY, Qiu WQ, Smith CE, Parnell LD, Jiang ZY, Ordovas JM, Tucker KL, Lai CQ (2012) Association between BDNF rs6265 and obesity in the Boston Puerto Rican Health Study. J Obes. 2012:102942. 
16. Sustar A, Nikolac Perkovic M, Nedic Erjavec G, Svob Strac D, Pivac N (2016) A protective effect of the BDNF Met/Met genotype in obesity in healthy Caucasian subjects but not in patients with coronary heart disease. Eur Rev Med Pharmacol Sci. 20(16):3417-26.

17. Akbarian SA, Salehi-Abargouei A, Pourmasoumi M, Kelishadi R, Nikpour P, Heidari-Beni M (2018) Association of Brain-derived neurotrophic factor gene polymorphisms with body mass index: A systematic review and meta-analysis. Adv Med Sci. 63(1):43-56.

18. [WHO] World Health Organization: Obesity and overweight (2020) [accessed 2020 Mar 26]. http://www.who.int/news-room/factsheets/detail/obesity-and-overweight.

19. Hruby A, Hu FB (2015) The Epidemiology of Obesity: A Big Picture. PharmacoEconomics. 33(7):673-89.

20. Busetto L, Dicker D, Azran C, Batterham RL, Farpour-Lambert N, Fried M, Hjelmesæth J, Kinzl J, Leitner DR, Makaronidis JM, et al. (2017) Practical Recommendations of the Obesity Management Task Force of the European Association for the Study of Obesity for the PostBariatric Surgery Medical Management. Obesity facts, 10(6):597-632.

21. Bastos EC, Barbosa EM, Soriano GM, dos Santos EA, Vasconcelos SM (2013) Determinants of weight regain after bariatric surgery. Arq Bras Cir Dig. 26(1):26-32.

22. Monaco-Ferreira DV, Leandro-Merhi VA (2017) Weight Regain 10 Years After Roux-en-Y Gastric Bypass. Obes Surg. 27(5):1137-44.

23. King WC, Hinerman AS, Belle SH, Wahed AS, Courcoulas AP (2018) Comprison of the Performance of Common Measures of Weight Regain After Bariatric Surgery for Association with Clinical Outcomes. JAMA. 320(15):1560-9.

24. Nonino CB, Oliveira BAP, Chaves RCP, Silva LTP, Pinhel MAS, Ferreira FC, Rocha GC, Donadelli SP, Marchini JS, Salgado-Junior W, et al. (2019) Is There Any Change in Phenotypic Characteristics Comparing 5 To 10 Years of Follow-Up in Obese Patients Undergoing Roux-EnY Gastric Bypass? Arq. Bras. Cir. Dig. 32(3), e1453.

25. Maleckas A, Gudaityte R, Petereit R, Venclauskas L, Velickiene D (2016) Weight regain after gastric bypass: etiology and treatment options. Gland Surg. 5(6):617-24.

26. Cambi MP, Marchesini SD, Baretta GA (2015) Post-bariatric surgery weight regain: evaluation of nutritional profile of candidate patients for endoscopic argon plasma coagulation. Arq Bras Cir Dig. 28(1):40-3.

27. Kushner RF, Sorensen KW (2015) Prevention of Weight Regain Following Bariatric Surgery. Curr Obes Rep. 4(2):198-206.

28. Conceição EM, Utzinger LM, Pisetsky EM (2015) Eating Disorders and Problematic Eating Behaviours Before and After Bariatric Surgery: Characterization, Assessment and Association with Treatment Outcomes. Eur Eat Disord Rev. 23(6):417-25.

29. Freitas S, Lopes CS, Coutinho W, Appolinario JC (2001) Translation and adaptation into Portuguese of the Binge-Eating Scale. Braz J Psychiat. 23(4):215-20

30. Davis C, Levitan RD, Yilmaz Z, Kaplan AS, Carter JC, Kennedy JL (2012) Binge eating disorder and the dopamine D2 receptor: genotypes and sub-phenotypes. Prog Neuropsychopharmacol Biol Psychiatry.38(2):328-35.

31. Beckers S, Peeters A, Zegers D, Mertens I, Van Gaal L, Van Hul W (2008) Association of the BDNF Val66Met variation with obesity in women. Mol Genet Metab. 95(1-2):110-2.

32. Jonsson EG, Nothen MM, Grunhage F, Farde L, Nakashima Y, Propping P, Sedvall GC (1999) Polymorphisms in the dopamine D2 receptor gene and their relationships to striatal dopamine receptor density of healthy volunteers. Mol Psychiatr. 4(3):290-6.

33. Cardel MI, Lemas DJ, Lee AM, Miller DR, Huo T, Klimentidis YC, Fernandez JR (2019) Taq1a polymorphism (rs1800497) is associated with obesity-related outcomes and dietary intake in a multi-ethnic sample of children. Pediatr Obes. 14(2):e12470.

34. Thaler L, Groleau P, Badawi G, Sycz L, Zeramdini N, Too A, Israel M, Joober R, Bruce KR, Steiger H (2012) Epistatic interactions implicating dopaminergic genes in bulimia nervosa (BN): relationships to eating- and personality-related psychopathology. Prog NeuroPsychoph. 39(1):120-8.

35. Peng S, Yu S, Wang Q, Kang Q, Zhang Y, Zhang R, Jiang W, Qian Y, Zhang H, Zhang M, et al. (2016) Dopamine receptor D2 and catecholO-methyltransferase gene polymorphisms associated with anorexia nervosa in Chinese Han population: DRD2 and COMT gene polymorphisms were associated with AN. Neurosci Lett. 616:147-51.

36. Nisoli E, Brunani A, Borgomainerio E, Tonello C, Dioni L, Briscini L, Redaelli G, Molinari E, Cavagnini F, Carruba MO (2007) D2 dopamine receptor (DRD2) gene Taq1A polymorphism and the eating-related psychological traits in eating disorders (anorexia nervosa and bulimia) and obesity. Eat Weight Disord. 12(2):91-6.

37. Rivera-Iniguez I, Panduro A, Ramos-Lopez O, Villasenor-Bayardo SJ, Roman S (2019) DRD2/ANKK1 Taql A1 polymorphism associates with overconsumption of unhealthy foods and biochemical abnormalities in a Mexican population. Eat Weight Disord. 24(5):835-44.

38. Blum K, Braverman ER, Wood RC, Gill J, Li C, Chen TJ, Taub M, Montgomery AR, Sheridan PJ, Cull JG (1996) Increased prevalence of the Taq I A1 allele of the dopamine receptor gene (DRD2) in obesity with comorbid substance use disorder: a preliminary report. Pharmacogenetics. 6(4):297-305.

39. Sun X, Luquet S, Small DM (2017) DRD2: Bridging the Genome and Ingestive Behavior. Trends Cogn Sci. 21(5):372-84.

Page $10 / 13$ 
40. Aliasghari F, Nazm SA, Yasari S, Mahdavi R, Bonyadi M (2020) Associations of the ANKK1 and DRD2 gene polymorphisms with overweight, obesity and hedonic hunger among women from the Northwest of Iran. Eat Weight Disord.

41. Davis C, Levitan RD, Kaplan AS, Carter J, Reid C, Curtis C, Patte K, Hwang R, Kennedy JL (2008) Reward sensitivity and the D2 dopamine receptor gene: A case-control study of binge eating disorder. Prog Neuropsychopharmacol Biol Psychiatry. 32(3):620-8.

42. Epstein LH, Temple JL, Neaderhiser BJ, Salis RJ, Erbe RW, Leddy JJ (2007) Food reinforcement, the dopamine D2 receptor genotype, and energy intake in obese and nonobese humans. Behav Neurosci. 121(5):877-86.

43. Davis CA, Levitan RD, Reid C, Carter JC, Kaplan AS, Patte KA, King N, Curtis C, Kennedy JL (2009) Dopamine for "wanting" and opioids for "liking": a comparison of obese adults with and without binge eating. Obesity (Silver Spring). 17(6):1220-5.

44. Palmeira L, Cunha M, Padez C, Alvarez M, Pinto-Gouveia J, Manco L (2019) Association study of variants in genes FTO, SLC6A4, DRD2, BDNF and GHRL with binge eating disorder (BED) in Portuguese women. Psychiatry Res. 273:309-11.

45. Fu LW, Zhang MX, Wu LJ, Gao LW, Mi J (2017) Gene-gene interaction on central obesity in school-aged children in China. Zhonghua Liu Xing Bing Xue Za Zhi. 38(7):883-888.

46. Zandona MR, Sangalli CN, Campagnolo PD, Vitolo MR, Almeida S, Mattevi VS (2017) Validation of obesity susceptibility loci identified by genome-wide association studies in early childhood in South Brazilian children. Pediatr Obes.12(1):85-92.

47. Wu L, Xi B, Zhang M, Shen Y, Zhao X, Cheng H, Hou D, Sun D, Ott J, Wang X, et al. (2010) Associations of six single nucleotide polymorphisms in obesity-related genes with BMI and risk of obesity in Chinese children. Diabetes. 59(12):3085-9.

48. Martínez-Ezquerro JD, Rendón-Macías ME, Zamora-Mendoza G, Serrano-Meneses J, Rosales-Rodríguez B, Escalante-Bautista D, Rodríguez-Cruz M, Sánchez-González R, Arellano-Pineda Y, López-Alarcón M, et al. (2017) Association Between the Brain-derived Neurotrophic Factor Val66Met Polymorphism and Overweight/Obesity in Pediatric Population. Arch Med Res. 48(7):599-608.

49. Monteleone P, Zanardini R, Tortorella A, Gennarelli M, Castaldo E, Canestrelli B, Maj M (2006) The 196G/A (val66met) polymorphism of the BDNF gene is significantly associated with binge eating behavior in women with bulimia nervosa or binge eating disorder. Neurosci Lett. 406(1-2):133-7.

50. Jung Y, Montel RA, Shen PH, Mash DC, Goldman D (2019) Assessment of the Association of D2 Dopamine Receptor Gene and Reported Allele Frequencies With Alcohol Use Disorders: A Systematic Review and Meta-analysis. JAMA Netw Open. 2(11):e1914940.

51. Noble EP (1994) Polymorphisms of the D2 dopamine receptor gene and alcoholism and other substance use disorders. Alcohol Suppl. 2:35-43.

52. Haerian BS. 2013. BDNF rs6265 polymorphism and drug addiction: a systematic review and meta-analysis. Pharmacogenomics. 14(16):2055-65.

53. Ponce G, Pérez-González R, Aragüés M, Palomo T, Rodríguez-Jiménez R, Jiménez-Arriero MA, Hoenicka J (2009) The ANKK1 kinase gene and psychiatric disorders. Neurotox Res. 16(1):50-9.

54. González-Castro TB, Pool-García S, Tovilla-Zárate CA, Juárez-Rojop IE, López-Narváez ML, Frésan A, Genis-Mendoza AD, PérezHernández N, Nicolini H (2019) Association between BDNF Val66Met polymorphism and generalized anxiety disorder and clinical characteristics in a Mexican population: A case-control study. Medicine (Baltimore). 98(11):e14838.

55. Perkovic MN, Mustapic M, Pavlovic M, Uzun S, Kozumplik O, Barisic I, Muck-Seler D, Pivac N (2013) Lack of association between brainderived neurotrophic factor Val66Met polymorphism and body mass index change over time in healthy adults. Neurosci. Lett. 545:12731.

\section{Figures}




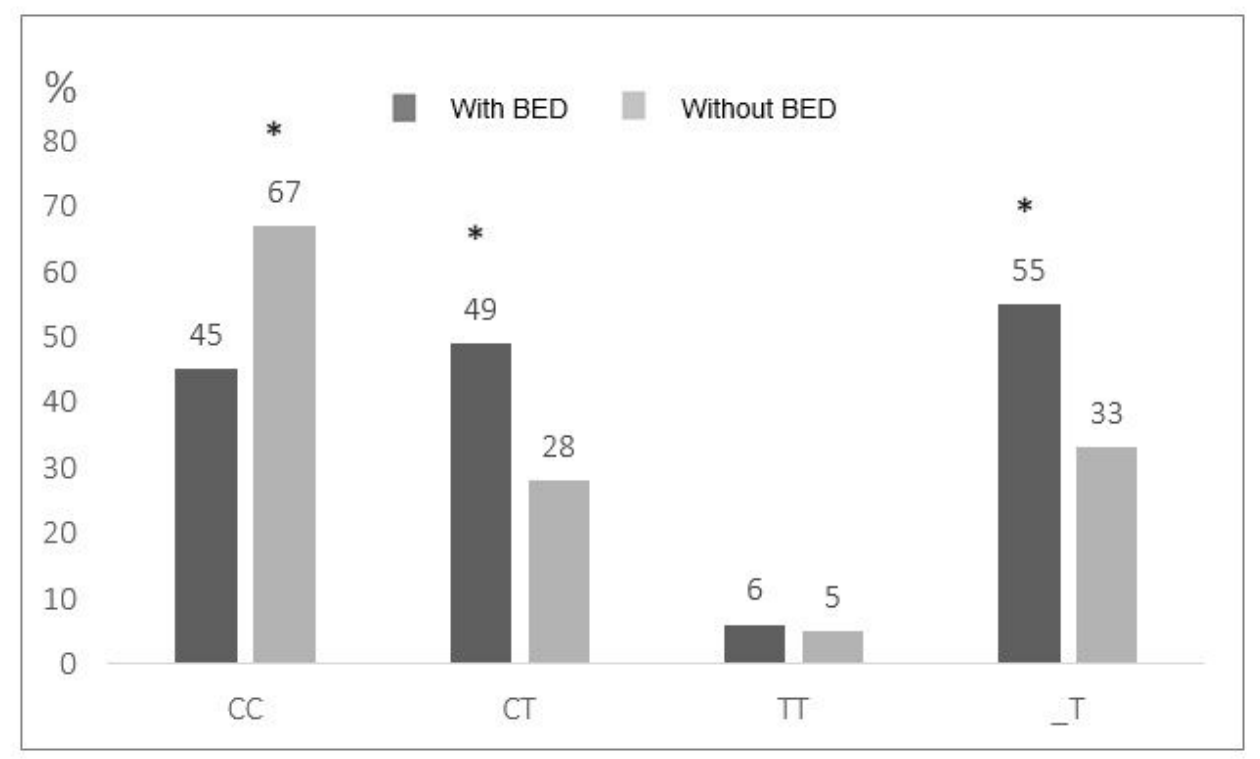

\section{Figure 1}

Genotype frequency of the rs1800497 polymorphism for the DRD2 gene in patients with and without Binge Eating Disorder (BED). * $=p<0.05$

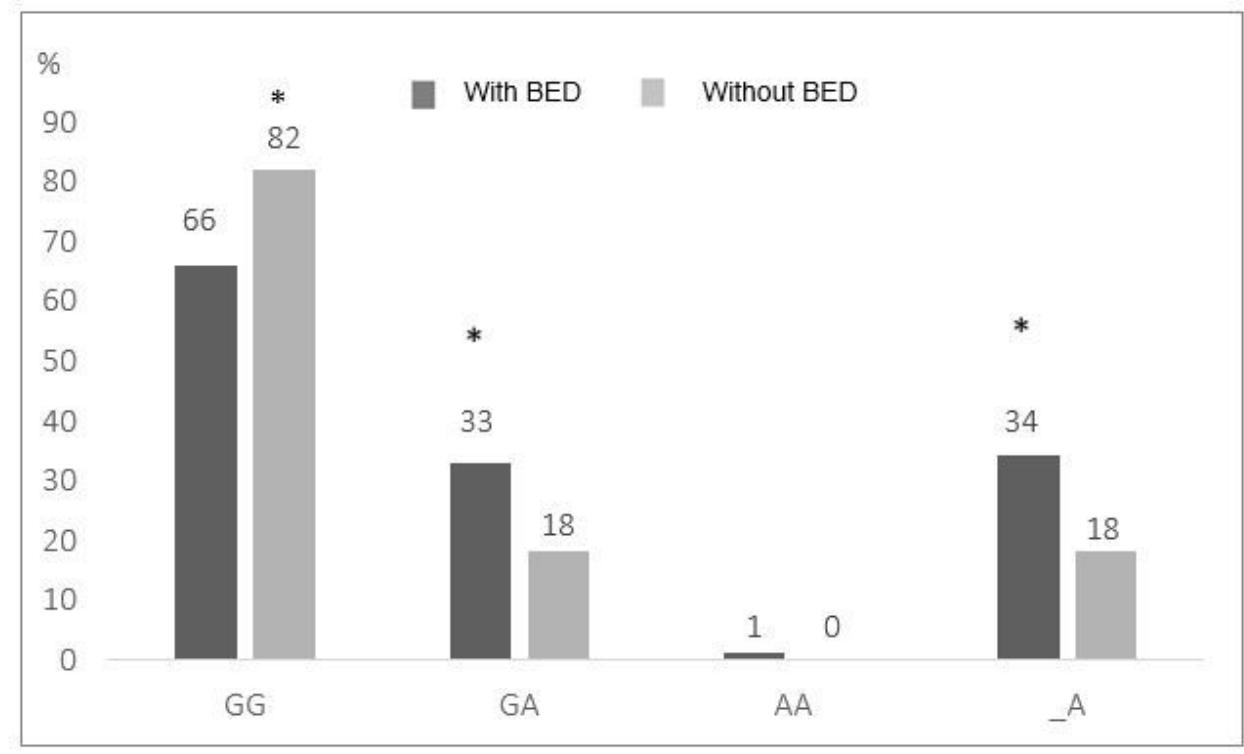

\section{Figure 2}

Genotype frequency of the rs6265 polymorphism for the BDNF gene in patients with and without Binge Eating Disorder (BED). * $=p<0.05$ 


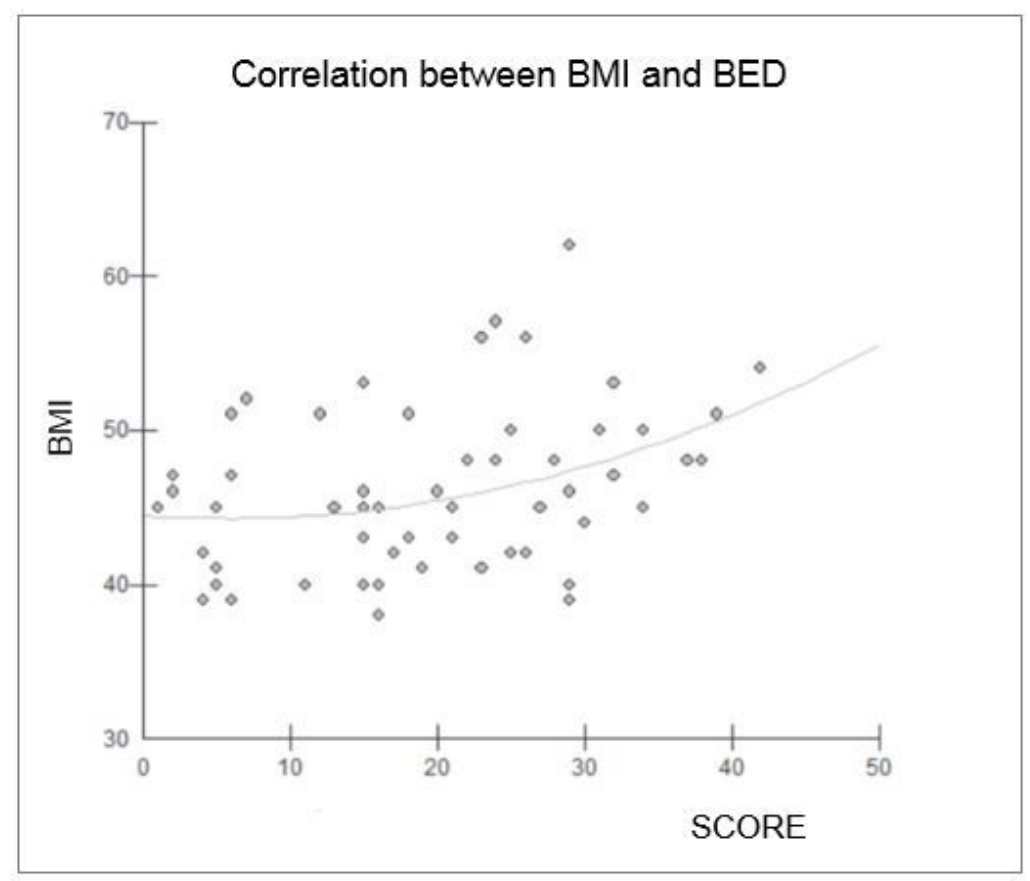

Figure 3

Correlation between BMI and BED $(r=0.320 ; p=0.015)$ 